\title{
No association between hand and foot temperature responses during local cold stress and rewarming
}

\author{
Lena Norrbrand $^{1}\left([) \cdot\right.$ Roger Kölegård $^{1} \cdot$ Michail E. Keramidas $^{1} \cdot$ Igor B. Mekjavic $^{2,3}$ • \\ Ola Eiken ${ }^{1}$
}

Received: 1 December 2016 / Accepted: 28 March 2017 / Published online: 18 April 2017

(c) The Author(s) 2017. This article is an open access publication

\begin{abstract}
Purpose The purpose was to examine whether associations exist between temperature responses in the fingers vs. toes and hand vs. foot during local cold-water immersion and rewarming phases.

Methods Seventy healthy subjects (58 males, 12 females) immersed their right hand or right foot, respectively, in $8^{\circ} \mathrm{C}$ water for $30 \mathrm{~min}$ (CWI phase), followed by a 15 -min spontaneous rewarming (RW) in $25^{\circ} \mathrm{C}$ air temperature.

Results Temperature was lower in the toes than the fingers during the baseline phase $\left(27.8 \pm 3.0\right.$ vs. $33.9 \pm 2.5^{\circ} \mathrm{C}$, $p<0.001$ ), parts of the CWI phase (min 20-30: $8.8 \pm 0.7$ vs. $9.7 \pm 1.4^{\circ} \mathrm{C}, p<0.001$ ), and during the RW phase (peak temperature: $22.5 \pm 5.1$ vs. $32.7 \pm 3.6^{\circ} \mathrm{C}, p<0.001$ ). Coldinduced vasodilatation (CIVD) was more common in the fingers than in the toes $(p<0.001)$. Within the first $10 \mathrm{~min}$ of CWI, $61 \%$ of the subjects exhibited a CIVD response in the fingers, while only $6 \%$ of the subjects had a CIVD response in the toes. There was a large variability of temperature responses both within and between extremities, and there was a weak correlation between finger- and toe temperature both during the CWI $(r=0.21, p=0.08)$ and the RW phases $(r=0.26, p=0.03)$.
\end{abstract}

Communicated by Narihiko Kondo.

Lena Norrbrand

lena.norrbrand@sth.kth.se

1 Department of Environmental Physiology, School of Technology and Health, KTH Royal Institute of Technology, Berzelius väg 13, SE-171 65 Solna, Sweden

2 Department of Automation, Biocybernetics and Robotics, Jozef Stefan Institute, Jamova 39, 1000 Ljubljana, Slovenia

3 Department of Biomedical Physiology and Kinesiology, Simon Fraser University, Burnaby, BC, Canada
Conclusions Results suggest that there is generally a lower temperature in the toes than the fingers after a short time of local cold exposure and that the thermal responses of the fingers/hands are not readily transferable to the toes/ foot.

Keywords CIVD $\cdot$ Finger - Toe $\cdot$ Water immersion Rewarming $\cdot$ Local cold injury $\cdot$ Cold tolerance

$\begin{array}{ll}\text { Abbreviations } \\ \text { CIVD } & \text { Cold-induced vasodilatation } \\ \text { CWI } & \text { Cold-water immersion } \\ \text { DAP } & \text { Diastolic arterial pressure } \\ \text { F-MT } & \text { Metatarsal region of the foot } \\ \text { H-MC } & \text { Metacarpal region of the hand } \\ \text { HR } & \text { Heart rate } \\ N & \text { Local skin-temperature wave in terms of }>1{ }^{\circ} \mathrm{C} \\ & \text { increase lasting for a minimum duration of } 3 \text { min } \\ \text { RW } & \text { Spontaneous (passive) rewarming phase } \\ \text { SAP } & \text { Systolic arterial pressure } \\ T_{\text {avg }} & \begin{array}{l}\text { Average temperature of each digit during every } \\ \text { phase }\end{array} \\ T_{\text {max }} & \text { Maximum temperature } \\ T_{\text {min }} & \text { Minimum temperature } \\ T_{\text {onset }} & \text { Onset time of the first CIVD response } \\ T_{\text {tympanic }} & \text { Tympanic temperature } \\ \text { WWI } & \text { Warm-water immersion } \\ \Delta T & \text { Difference between the lowest temperature } \\ & \text { recorded just before the CIVD and the highest } \\ & \text { temperature reached during the CIVD }\end{array}$

Abbreviations

CIVD Cold-induced vasodilatation

CWI Cold-water immersion

DAP Diastolic arterial pressure

F-MT Metatarsal region of the foot

H-MC Metacarpal region of the hand

HR Heart rate

increase lasting for a minimum duration of $3 \mathrm{~min}$

RW Spontaneous (passive) rewarming phase

SAP Systolic arterial pressure

$T_{\text {av }}$

$T_{\max }$

$T_{\min }$

$T_{\text {onset }}$

$T_{\text {tympanic }}$

WWI

temperature reached during the CIVD 


\section{Introduction}

Prolonged exposure to low ambient temperatures may induce cold injuries, particularly in the hands and feet; the feet appear to be more vulnerable than the hands (DeGroot et al. 2003; Juopperi et al. 2002). Considering the amount of people exposed to harsh, or even extreme, weather conditions in a rather elective manner, either for occupational or recreational reasons (e.g., military personnel and mountaineers), the establishment and evaluation of a sensitive prediction tool constitute an essential step for the prevention of cold injuries.

Based on the premise that the cold-induced vasodilatation (CIVD) response, a "paradoxical" rise in the digits circulation shortly upon exposure to cold (Lewis 1930), might serve as a cryoprotective mechanism (Wilson and Goldman 1970; Mathew et al. 1973, 1974), it has been suggested that the temperature reaction of the digits in one limb (Van der Struijs et al. 2008), or even one digit (Daanen and van der Struijs 2005), to a local cold stimulus might reflect the overall susceptibility to cold injury, regardless of the testing region. Thus, Daanen and van der Struijs (2005) have advocated that the employment of a short-term cold-provocation test in one finger could be used as a means to stratify individuals into groups possessing low and high risks of cold injury. This notion has since been challenged by Cheung and Mekjavic (2007) who showed that, in a small group of healthy males, the temperature responses during cold stress are not homogenous across, nor between, the hand and foot, and therefore, any generalization of the thermal response stemming from a single region seems unwarranted (Cheung and Mekjavic 2007). This conclusion is also in line with that of Chen et al. (1996).

Not only the temperature reactions during local cooling, but also the thermal responses during a period of spontaneous (passive) rewarming ensuing a local cold stimulus have been considered as an approach to detect the sensitivity to cold (Davey et al. 2013; Eglin et al. 2013) and to indicate susceptibility to cold injury (Ahle et al. 1990; Brändström et al. 2008; Ruijs et al. 2008). Brändström et al. (2008) have argued that the rewarming response of the hand following a 10-min local cooling can be generalized to all extremities predicting the risk of local cold injury, and hence can be used, in a military setting, as a tool to select individuals for redeployment to warmer assignments. Yet, although there are indications that the rewarming responses of the hand may differ from those of the foot (cf. Morrison et al. 2015; Rissanen and Rintamäki 2009), to our knowledge, no study has hitherto systematically examined in a large group of individuals whether the rewarming response of the hand is transferable to the foot. In the aforementioned studies by Chen et al. (1996) and Cheung and Mekjavic (2007), small groups of individuals were investigated ( $n=8$ and $n=10$, respectively) and only during the cooling phase.

Accordingly, the purpose of the present study was to map the temperature responses of all exposed segments of the hand and foot during and after local cold stress in a large cohort of young individuals and to examine whether the responses of one limb would be transferable to the other limb. Based on results in previous studies (Chen et al. 1996; Cheung and Mekjavic 2007; Morrison et al. 2015; O'Brien 2005; Rissanen and Rintamäki 2009), we hypothesized that: (1) the foot would reach lower temperatures than the hand during both the cold-water immersion and rewarming phases and that (2) the temperature responses of the hand would not be associated with those of the foot neither during nor after the local cold stress.

\section{Methods}

\section{Subjects}

Fifty-eight male and twelve female cadets of the Swedish Armed Forces participated in the study $(n=70$, age: $23.2 \pm 2.4$ years, height: $1.80 \pm 0.07 \mathrm{~m}$, weight: $78.8 \pm 9.9 \mathrm{~kg}$, BMI: $24.4 \pm 2.5 \mathrm{~kg} \mathrm{~m}^{-2}$ ). Subjects were healthy, had no history of any cold injury, and no previous experience with cold-exposure experiments. They were informed in detail about the experimental procedures and gave their written consent. They were instructed not to engage in any strenuous activity, to refrain from consuming any caffeinated product for a day before, and not to use tobacco within $6-8 \mathrm{~h}$ prior to the test. The experimental protocol was approved by the Humans Ethics Committee of Stockholm and conformed to the Declaration of Helsinki.

\section{Experimental protocol}

Subjects performed, in a counterbalanced order and separated by a 15-min interval, two cold-water immersion tests: once they immersed the right hand, and on the other occasion, the right foot. Subjects were dressed in T-shirt and shorts (they also had socks during the hand cold test), and remained in a sitting position throughout each test. Prior to the start of the test, subjects were accustomed to the conditions of the laboratory for $\sim 20 \mathrm{~min}$. The mean temperature and relative humidity in the laboratory were $25.0 \pm 0.5^{\circ} \mathrm{C}$ and $36 \pm 9 \%$, respectively. All tests were performed between November and February.

Each test commenced with a 5-min baseline phase, during which the subject rested with the test limb dry in room temperature on a support (baseline phase). After this, the limb was covered with a thin plastic bag (thickness of $0.025 \mathrm{~mm}$ ), sealed with air-permeable tape to the skin 
( $\sim 10 \mathrm{~cm}$ above the wrist and ankle, respectively), whereafter it was immersed in warm water $\left(35^{\circ} \mathrm{C}\right.$ ) for 5 min (WWI phase). The hand was immersed up to the ulnar and radial styloids, and the foot up to the tibial and fibular styloids. Subsequently, the limb was removed from the warm-water tank, and placed without the plastic bag on the limb support for $\sim 1 \mathrm{~min}$, during which infrared-thermal images were obtained (see below for details). Thereafter, the hand/ foot was covered with a new plastic bag and immersed in a tank containing cold water $\left(8^{\circ} \mathrm{C}\right)$ for $30 \mathrm{~min}$ (CWI phase). The temperature of the water was maintained by means of a cooling system (Cylinda, Elektroscandia Sverige AB, Sollentuna, Sweden), and a pump continuously stirred the water. After completion of the CWI phase, the limb was removed from the water, dried with a towel, if necessary, and a 15-min spontaneous rewarming (RW) phase ensued, while the limb was resting as in the baseline phase. Throughout each test, the subject was instructed to keep the contralateral (non-immersed) limb immobile on the support.

\section{Instrumentation}

\section{Thermocouple probes}

During each test, digit skin temperatures of the immersed limb were measured with copper-constantan (T-type) thermocouple probes (Physitemp Instruments Inc., Clifton, NJ, USA), attached to the middle of the volar side of the distal phalanx of each digit. An additional thermocouple probe was placed at the center of the dorsal metacarpal and metatarsal region of the hand (H-MC) and foot (F-MT), respectively. The primary insulation of the thermocouples was polytetrafluoroethylene; the non-insulated welded junction of each thermocouple was attached directly to the skin with thin air-permeable tape (Tegaderm, 3M, Healthcare, St. Paul, MN, USA). Skin temperatures were sampled every second with an NI USB-6215 (National Instruments, Austin, Texas, USA) data acquisition board, operated with the TestPoint software (TestPoint $v 7^{\circledR}$, Norton, Massachusetts, USA). Following a manual check of the raw data, a custommade computer program (TestPoint) was used to calculate the average temperature $\left(T_{\text {avg }}\right)$ of each digit during every phase, as well as the minimum $\left(T_{\min }\right)$ and maximum $\left(T_{\max }\right)$ temperatures reached during the CWI and RW phases. The same program was also used to detect any digit CIVD response, defined as a local skin-temperature wave $(N)$ in terms of $>1{ }^{\circ} \mathrm{C}$ increase lasting for a minimum duration of $3 \mathrm{~min}$. In case of a CIVD response, the following parameters were determined: (1) the temperature amplitude $(\Delta T)$, which was the difference between the lowest temperature recorded just before the CIVD and the highest temperature reached during the CIVD and (2) the onset time $\left(t_{\text {onset }}\right)$ of the first CIVD response.

\section{Infrared thermography}

During the dry phases of the experiment, i.e., at the end of the baseline, immediately after the WWI, and during the RW phase (at minutes 1, 5, 10 and 15), skin temperatures on the volar and dorsal side of the hand/foot, that was to be or had been immersed, were recorded with an infrared camera (FLIR T365, FLIR Systems AB, Danderyd, Sweden), which was calibrated automatically. Infrared images of the contralateral, non-immersed limb were also taken during the baseline, after the WWI phase, and at the first and fifth minute of the CWI phase. The field of the camera's view was $25^{\circ} \times 19^{\circ}$, the spatial resolution was $1.36 \mathrm{mrad}$, the spectral range $7.5-13 \mu \mathrm{m}$, and the infrared detector resolution was $320 \times 240$ pixels. The distance between the camera and the extremity was $\sim 60 \mathrm{~cm}$. The thermal images were analyzed using the ThermaCam Researcher PRO 2.10 software (FLIR Systems AB, Danderyd, Sweden). In 69 of the subjects (for technical reasons, the data from one subject could not be analyzed in the foot that had been immersed), $T_{\text {avg }}$ of the immersed hand was determined for the following anatomical areas: (1) the volar and the dorsal side of the distal phalanx of each finger; (2) the total palm; and (3) dorsal metacarpal area. In the same subjects, $T_{\text {avg }}$ of the immersed foot was determined for the following areas: (1) the volar and the dorsal side of the distal phalanx of each toe; (2) the total sole; and (3) dorsal metatarsal area. In all 70 subjects, $T_{\text {avg }}$ of the contralateral, non-immersed hand, and foot was determined for the following anatomical areas: (1) the volar side of the distal phalanx of finger II; (2) the total palm; (3) the volar side of the distal phalanx of toe II; and (4) the total sole.

\section{Tympanic temperature}

During the baseline and RW phases, the tympanic temperature $\left(T_{\text {tympanic }}\right)$ was measured using an infrared thermometer (ThermoScan IRT 6012, Braun, Kronberg, Germany). Two consecutive measurements were obtained each time, and the higher of the two values was used for subsequent analysis.

\section{Haemodynamic variables}

Heart rate (HR), systolic (SAP), and diastolic (DAP) arterial pressures were measured at 5-min intervals using an automated oscillometric sphygmomanometer (Omron M6, Kyoto, Japan) with the cuff positioned around the mid portion of the left upper arm. 
Fig. 1 Average temperature (Tavg) of (a) the distal phalanx of the volar side of all fingers and toes and (b) the dorsal metacarpal and metatarsal region of the right hand and foot, respectively, obtained during the cold-water immersion test. Values are mean $\pm \mathrm{SD}$.

Data are averaged every $30 \mathrm{~s}$

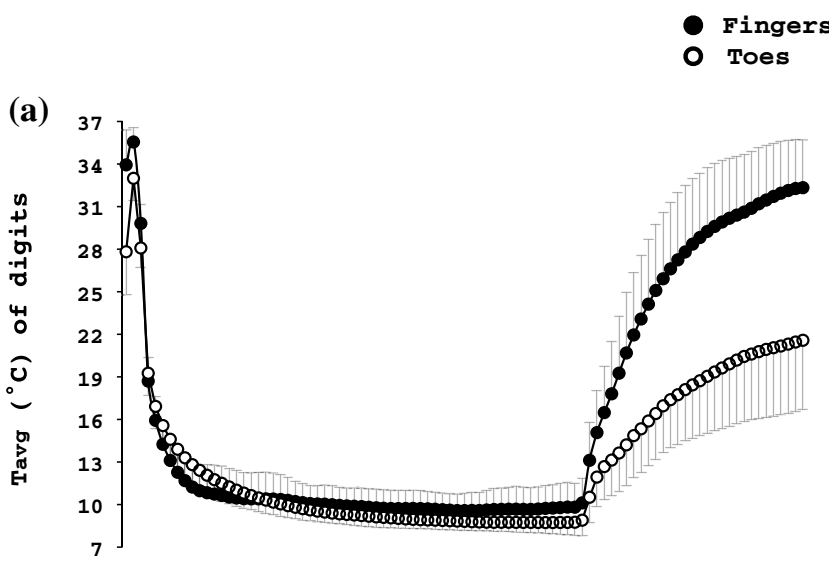

(b)

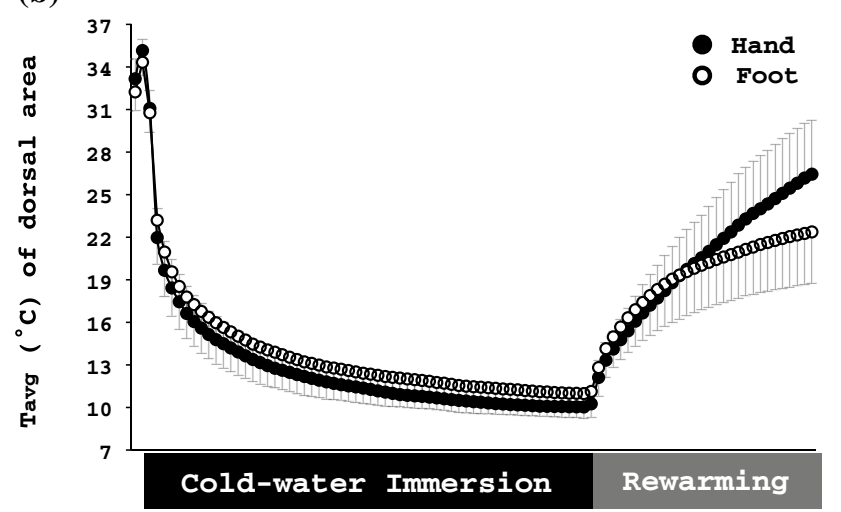

Evans guidelines (Evans 1996): $r=0.00-0.19$ : very weak, 0.20-0.39: weak, 0.40-0.59: moderate, 0.60-0.79: strong, $0.80-1.0$ : very strong. Differences in $N$, thermal comfort, thermal sensation, and local pain were evaluated with a Wilcoxon matched pairs nonparametric test. The alpha level of significance was set a priori at 0.05 .

\section{Results}

\section{Temperature responses}

\section{Immersed limb}

Soft, Inc., Tulsa, Oklahoma, USA). All variables are presented as mean $\pm \mathrm{SD}$, unless otherwise indicated. A twoway general linear model repeated measures ANOVA was used to evaluate the thermal (limb $\times$ region), and haemodynamic (limb $\times$ phase) responses within and between the two tests. When ANOVA revealed a significant $F$ ratio for interaction and/or main effect, pairwise comparisons were performed with Tukey HSD post hoc test. Pearson product-moment correlation was used to evaluate the relation between selected physiological variables. Magnitudes of correlations were interpreted qualitatively using
Baseline and WWI phases During both phases, the toes (baseline: $27.8 \pm 3.0^{\circ} \mathrm{C}$, WWI: $33.0 \pm 1.6^{\circ} \mathrm{C}$ ) and F-MT (baseline: $32.2 \pm 1.3{ }^{\circ} \mathrm{C}$, WWI: $34.4 \pm 0.8^{\circ} \mathrm{C}$ ) were colder $(p<0.001)$ than the fingers (baseline: $33.9 \pm 2.5^{\circ} \mathrm{C}$, WWI: $35.6 \pm 1.0^{\circ} \mathrm{C}$ ) and $\mathrm{H}-\mathrm{MC}$ (baseline: $33.2 \pm 1.4^{\circ} \mathrm{C}$, WWI: $\left.35.2 \pm 0.8^{\circ} \mathrm{C}\right)$, respectively.

CWI phase Upon immersion to the cold water, all regions of the hand cooled faster than those of the foot (hand: $-5.5 \pm 0.4^{\circ} \mathrm{C} \cdot \mathrm{min}^{-1}$; foot: $-4.6 \pm 0.7^{\circ} \mathrm{C} \cdot \mathrm{min}^{-1} ; p<0.001$; 


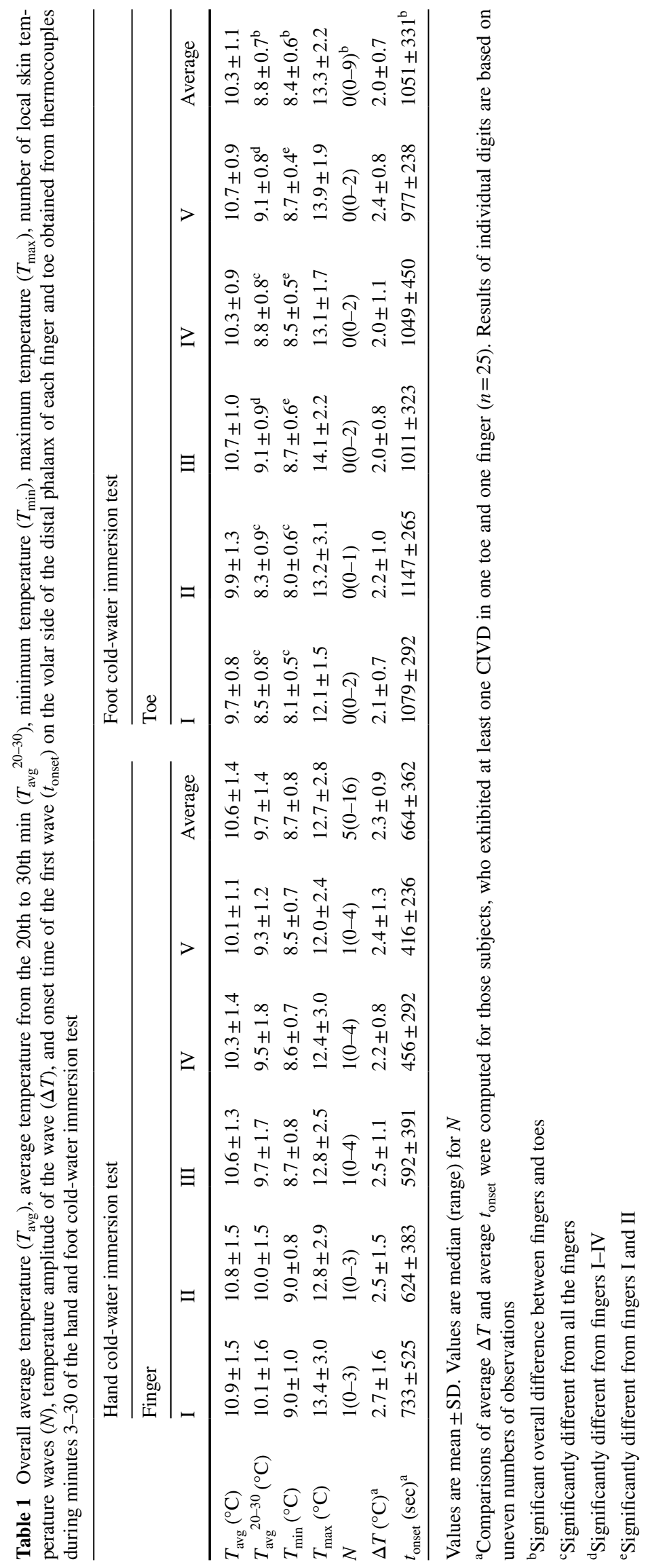


Fig. 1). However, after the third minute until the end of the CWI phase, the toes tended to be colder than the fingers ( $p=0.07$; Table 1); especially, during the last $10 \mathrm{~min}$ $(p<0.001)$. Conversely, $\mathrm{H}-\mathrm{MC}\left(12.3 \pm 1.0^{\circ} \mathrm{C}\right)$ was colder $(p<0.001)$ than F-MT $\left(13.4 \pm 2.1^{\circ} \mathrm{C}\right)$. Between the third minute until the end of the CWI phase, finger I and II were warmer than the other fingers $(p \leq 0.002)$, and toe III, IV, and V were warmer than toe I and II $(p<0.001$, Table 1).

The number of CIVD responses was higher in the fingers than in the toes $(p<0.001$; Table 1). $43(61 \%)$ subjects exhibited a CIVD response, at least in 1 finger, within the first 10 min of the CWI phase, whereas only 4 subjects (6\%) exhibited a CIVD response in the toes during the same time period. All in all, $64(91 \%)$ subjects demonstrated a total of 397 CIVD responses in the fingers, where 30 (43\%) subjects exhibited CIVD responses in all fingers. For the toes, $26(37 \%)$ subjects demonstrated a total of 70 CIVD responses, while only $3(4 \%)$ subjects exhibited CIVD responses in all toes. $T_{\min }$ was lower in the toes than in the fingers $(p<0.001$; Table 1$)$; there was no difference between the limbs as regards $T_{\max }(p=0.10$; Table 1$)$.

$R W$ phase At the onset of the RW phase, $T_{\text {avg }}$ was higher $(p<0.001)$ in the fingers $\left(9.9 \pm 2.0^{\circ} \mathrm{C}\right)$ than in the toes $\left(8.8 \pm 1.2^{\circ} \mathrm{C}\right.$, Table 2$)$, but it was lower $(p<0.001)$ in the $\mathrm{H}-\mathrm{MC}\left(10.1 \pm 2.0^{\circ} \mathrm{C}\right)$ than in the F-MT $\left(11.1 \pm 1.8^{\circ} \mathrm{C}\right)$. The overall rewarming response of the hand was greater than that of the foot $(p<0.001$; Table 2; Figs. 2, 3). The fingers and H-MC reached higher Tmax than the toes and F-MT, respectively (Fingers $=32.7 \pm 3.6{ }^{\circ} \mathrm{C}$, Toes $=22.5 \pm 5.1^{\circ} \mathrm{C}$; $\mathrm{H}-\mathrm{MC}=27.0 \pm 3.9^{\circ} \mathrm{C}$, $\left.\mathrm{F}-\mathrm{MT}=23.6 \pm 3.7^{\circ} \mathrm{C} ; p<0.001\right)$. During the RW phase, finger II was warmer than finger IV and V $(p \leq 0.003)$, and toe I was warmer than toe III, IV, and V $(p<0.001$, Table 2).

Correlations A weak correlation was noted between the fingers baseline $T_{\text {avg }}$ and their $T_{\text {avg }}$ during the CWI $(r=0.26, p=0.03)$ and the RW $(r=0.32, p<0.01)$ phases (Fig. 4a). The RW $T_{\text {avg }}$ of the fingers was strongly related to their CWI $T_{\text {avg }}(r=0.70, p<0.001$; Fig. 4a). A weak correlation was observed between the toes baseline $T_{\text {avg }}$ and their CWI $T_{\text {avg }}(r=0.37, p<0.001$; Fig. 4b). The RW $T_{\text {avg }}$ of the toes was moderately correlated to their CWI $T_{\text {avg }}(r=0.43, p<0.001)$, but not to their baseline $T_{\text {avg }}$ $(r=0.19 ; p=0.12)$ (Fig. 4b).

There was a statistical tendency for a weak correlation between the fingers and toes $T_{\text {avg }}$ during the CWI phase $(r=0.21, p=0.08$; Fig. 5a). A weak correlation was detected between the RW $T_{\text {avg }}$ of the digits of the two limbs ( $r=0.26, p=0.03$; Fig. $5 b$ ).

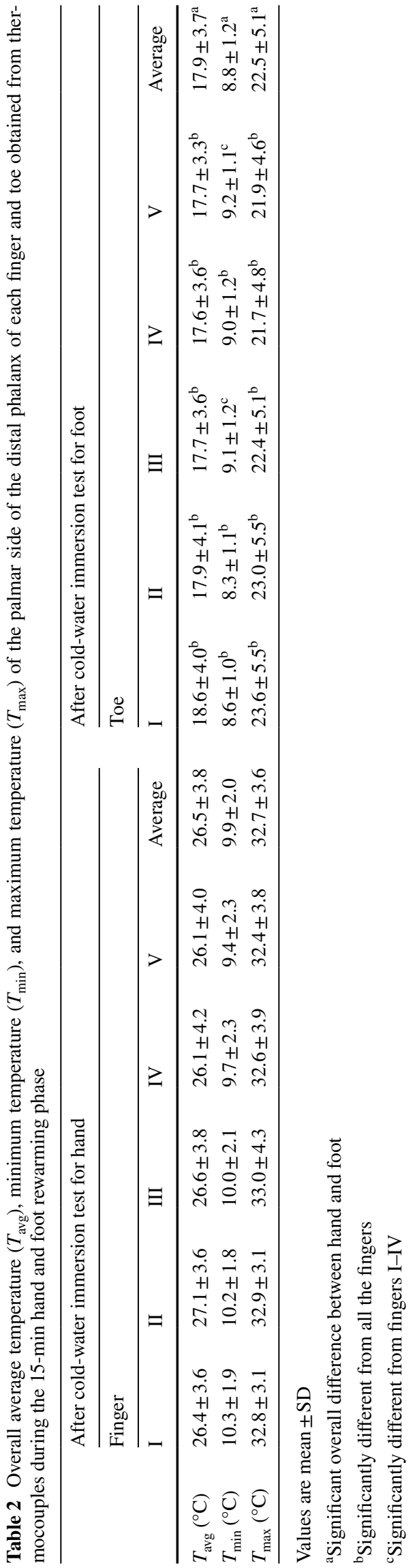


Fingers

O Toes

(a)

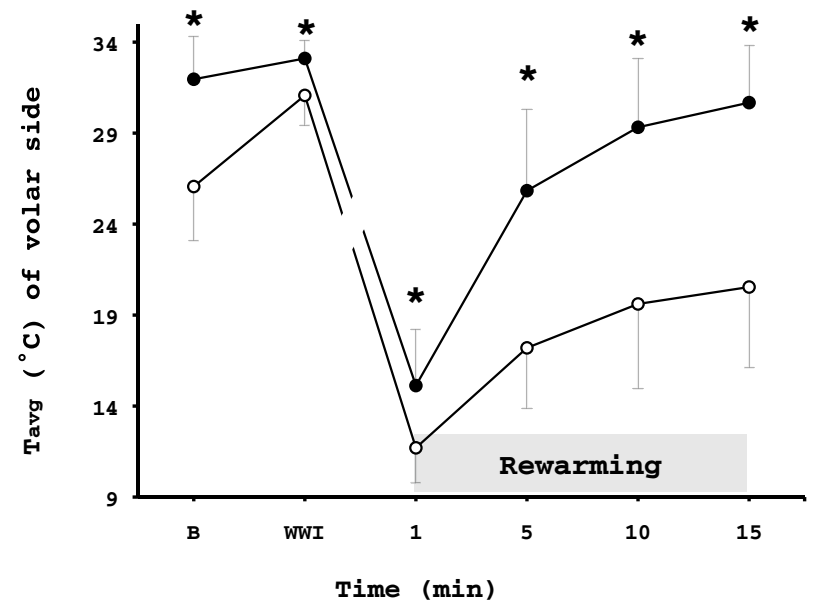

(c)

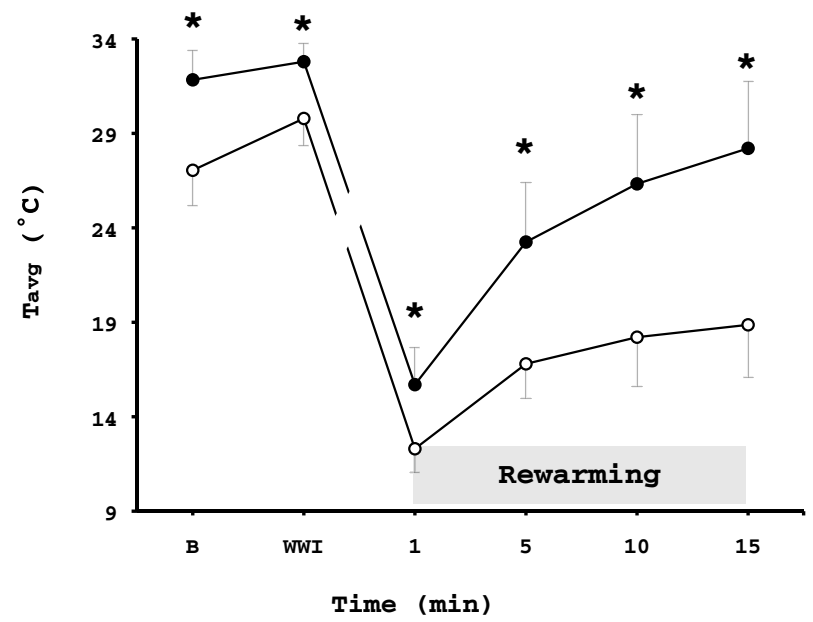

Fig. 2 Thermography results showing average temperature $\left(T_{\text {avg }}\right)$ of (a) the volar and (b) the dorsal side of the distal phalanx of the fingers and toes, (c) the total area of palm and sole, and (d) the total dorsal metacarpal/metatarsal area of the right hand and foot during

\section{Non-immersed limb}

Throughout the tests, the non-immersed hand (finger II: $31.0 \pm 3.0^{\circ} \mathrm{C}$, palm: $32.5 \pm 1.7^{\circ} \mathrm{C}$ ) was warmer $(p<0.001)$ than the non-immersed foot (toe II: $26.2 \pm 4.3{ }^{\circ} \mathrm{C}$, sole: $27.9 \pm 2.6{ }^{\circ} \mathrm{C}$ ). The cold stimulus did not alter $T_{\text {avg }}$ of the non-immersed palm or sole $(p>0.05)$. However, upon immersion to cold water, there was a transient drop of $\sim 1^{\circ} \mathrm{C}$ in Tavg of finger II $(p=0.01) . T_{\text {avg }}$ of toe II was also slightly reduced $\left(\sim 0.2^{\circ} \mathrm{C}\right)$, but the drop was not statistically significant ( $p>0.05$; Fig. 6). (b)

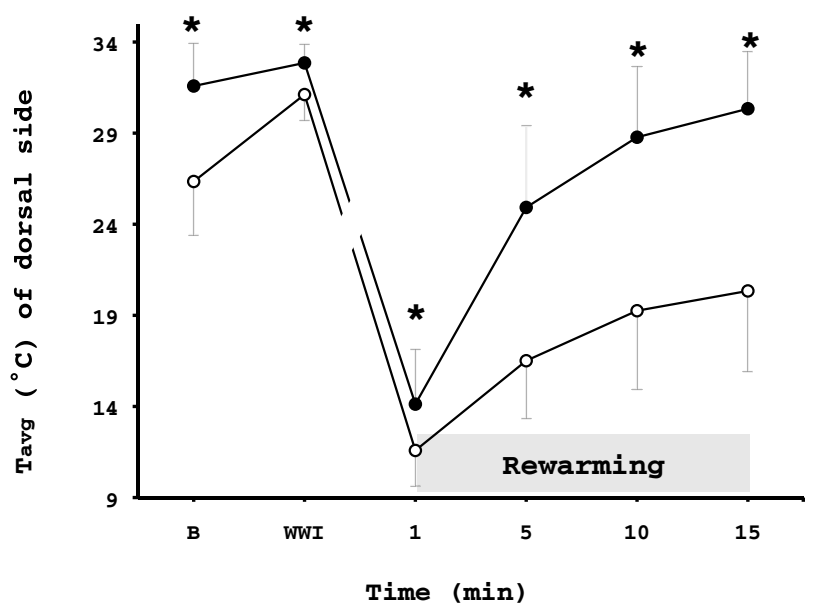

(d)

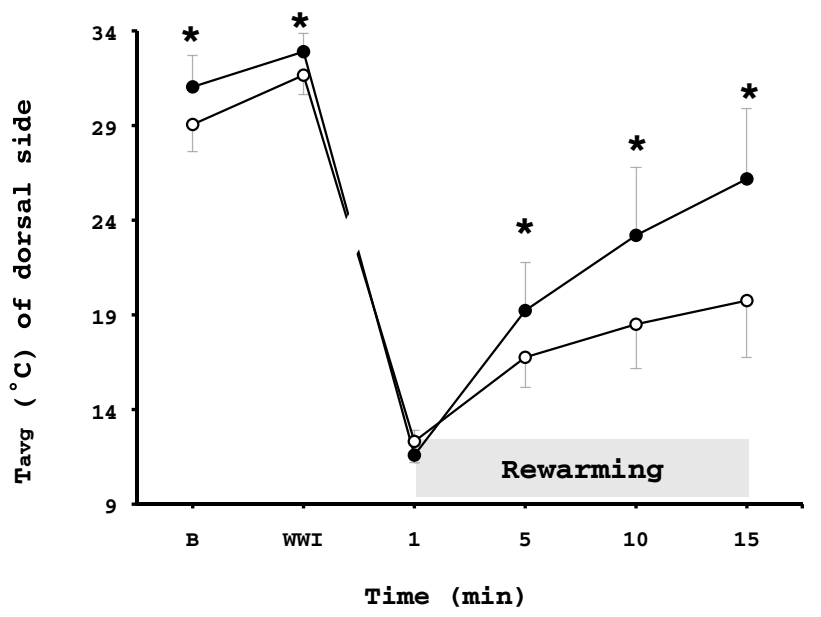

the spontaneous rewarming phase. Values are mean \pm SD. $n=69$. *Significant difference between hand and foot $(p<0.001)$. B: a 5-min baseline phase, $W W I$ : a 5-min warm-water immersion phase, $R W$ : a 15-min rewarming phase

\section{Ttympanic}

There was no difference in $T_{\text {tympanic }}$ between the tests (hand test: baseline $=36.5 \pm 0.4^{\circ} \mathrm{C}, \mathrm{RW}=36.5 \pm 0.4^{\circ} \mathrm{C}$; foot test: baseline $=36.5 \pm 0.4^{\circ} \mathrm{C}, \mathrm{RW}=36.6 \pm 0.4^{\circ} \mathrm{C} ; p>0.05$ ).

\section{Haemodynamic responses}

\section{Heart rate}

Baseline and WWI average values for HR were similar in the hand and foot test, whereas during the 
(a)

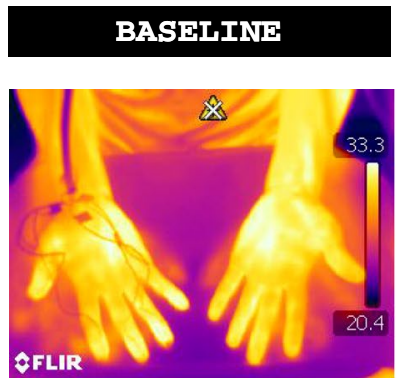

5-min REWARMING

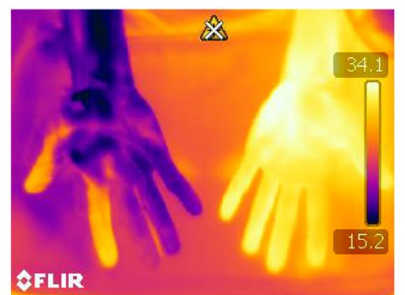

(b)
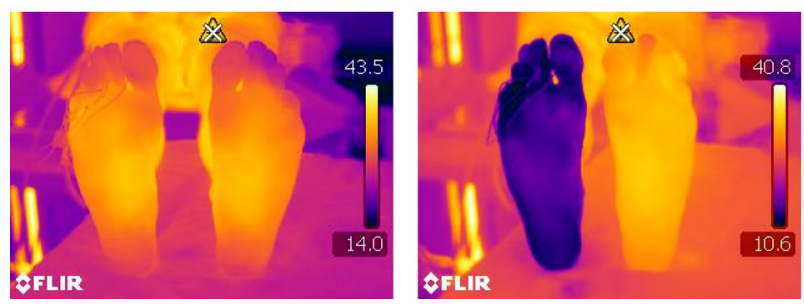

\section{0-min REWARMING}
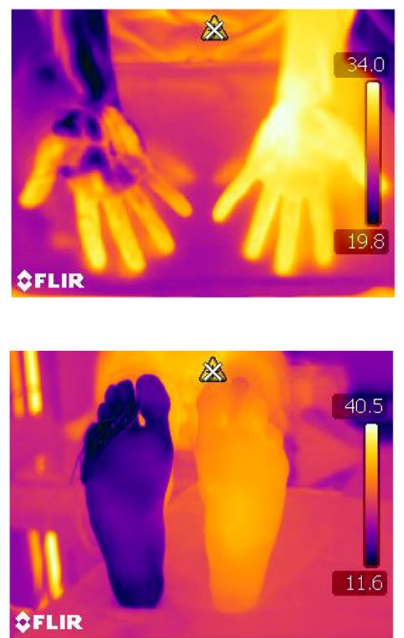

\section{5-min RFWARMING}
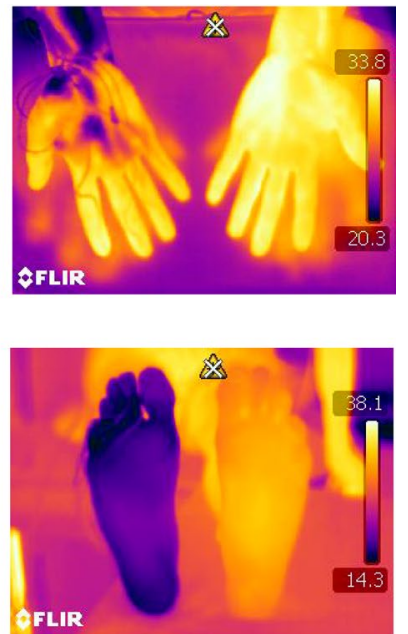

Fig. 3 Representative infrared-thermal images from a single subject during the baseline and the 15-min rewarming response of (a) the hand and (b) the foot. Color coding of temperatures are indicated on the right-hand side; the brighter colors represent a warmer limb (yellow), and the darker colors represent a colder limb (dark purple). Note (1) the rate of rewarming in the hand vs. the foot and (2) the distal to proximal rewarming pattern for the fingers

the foot felt colder than the hand [hand test: 5 -min $\mathrm{RW}=3$ (range 1-7), 10-min RW=4 (1-6), 15-min RW=4 (2-7); foot test: 5-min $\mathrm{RW}=2$ (1-5), 10-min $\mathrm{RW}=3$ (1-5), 15-min $\mathrm{RW}=3.5(1-6) ; p<0.001]$.

\section{Thermal comfort}

During the last $5 \mathrm{~min}$ of CWI and the first $5 \mathrm{~min}$ of the RW, subjects felt more uncomfortable in the foot than the hand [hand test: $25-\mathrm{min} \mathrm{CWI}=2$ (1-4), 30-min CWI=2 (1-4), 5 -min $\mathrm{RW}=1.25$ (1-4); foot test: $25-\min \mathrm{CWI}=3$ (1-4), $30-\min \mathrm{CWI}=3(1-4), 5-\min \mathrm{RW}=2(1-4) ; p<0.001]$.

There were no differences between the hand and foot tests as regards SAP (hand test: baseline $=119 \pm 11 \quad \mathrm{mmHg}, \quad \mathrm{WWI}=119 \pm 11 \quad \mathrm{mmHg}$, $\mathrm{CWI}=122 \pm 10 \mathrm{mmHg}, \mathrm{RW}=118 \pm 9 \mathrm{mmHg}$; foot test: baseline $=122 \pm 11 \mathrm{mmHg}, \quad \mathrm{WWI}=118 \pm 11 \mathrm{mmHg}$, $\mathrm{CWI}=122 \pm 11 \mathrm{mmHg}, \mathrm{RW}=119 \pm 10 \mathrm{mmHg}$ ) or DAP (hand test: baseline $=75 \pm 9 \mathrm{mmHg}, \mathrm{WWI}=76 \pm 7 \mathrm{mmHg}$, $\mathrm{CWI}=79 \pm 7 \mathrm{mmHg}, \mathrm{RW}=76 \pm 7 \mathrm{mmHg}$; foot test: baseline $=78 \pm 8 \quad \mathrm{mmHg}, \quad \mathrm{WWI}=76 \pm 8 \quad \mathrm{mmHg}$, $\mathrm{CWI}=80 \pm 6 \mathrm{mmHg}, \mathrm{RW}=78 \pm 6 \mathrm{mmHg}$ ) responses. During the hand and foot tests, both SAP $(p<0.002)$ and DAP $(p<0.002)$ increased during the first minute of CWI (Fig. 7).

\section{Psychometric responses}

\section{Thermal sensation}

During both CWI phases, subjects reported similar values of thermal sensation; however, during the RW phase,

\section{Pain}

During the last 5 min of CWI and the first 5 min of the RW, subjects experienced more pain in the foot than the hand [hand test: $25-\min \mathrm{CWI}=2.5$ (0-9), 30-min CWI = 2 (0-9), 5-min $\mathrm{RW}=0$ (0-9); foot test: 25-min CWI=3 (0-9), $30-\min \mathrm{CWI}=3$ (0-9), 5-min $\mathrm{RW}=1(0-8) ; p<0.001]$.

\section{Discussion}

Based on the presumption that the CIVD response of the digits has a cryoprotective function (Mathew et al. 1973, 1974; Wilson and Goldman 1970) and that an efficient RW response will also protect against cold injury (Francis and Golden 1985), it has been suggested that, in any given individual, the temperature reaction of the digits of one limb, 


\section{HAND COLD-TEST}

(a)
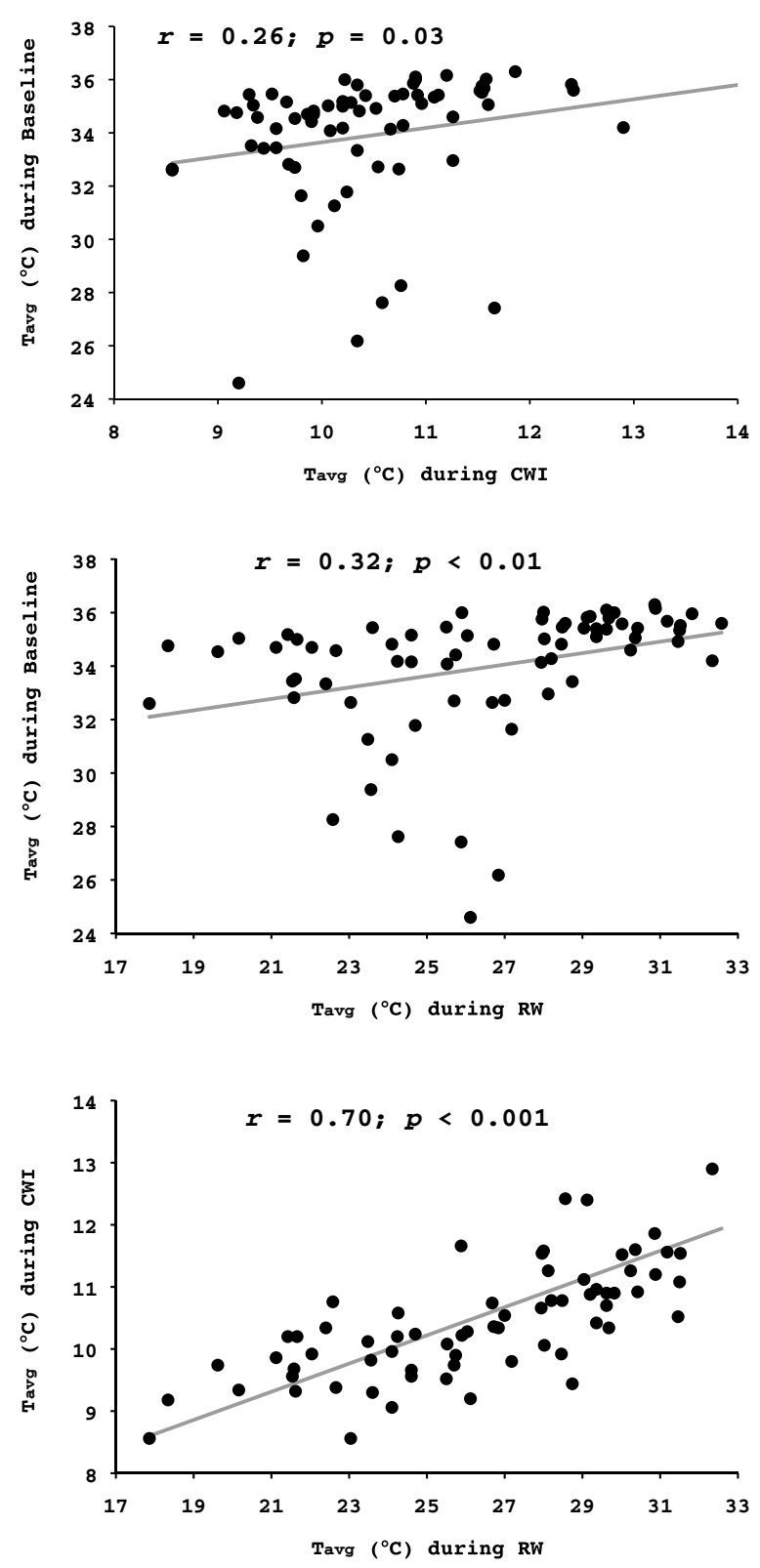

Fig. 4 Pearson's product-moment correlation between the average temperature $\left(T_{\mathrm{avg}}\right)$ during the 5-min baseline and the 30-min coldwater immersion phase (upper graphs), and the 5-min baseline and the 15-min spontaneous rewarming phase (middle graphs), and the

or one digit, during (Daanen and van der Struijs 2005; Van der Struijs et al. 2008) or after (Brändström et al. 2008) a local cold stress is representative of all regions and hence can be used as a means to predict this individual's general vulnerability to cold injury. Still, a number of reports (Chen et al. 1996; Cheung and Mekjavic 2007; Reynolds et al. 2007) have, by describing the cold-induced thermal reactions in small groups of healthy individuals, indicated

\section{FOOT COLD-TEST}

(b)
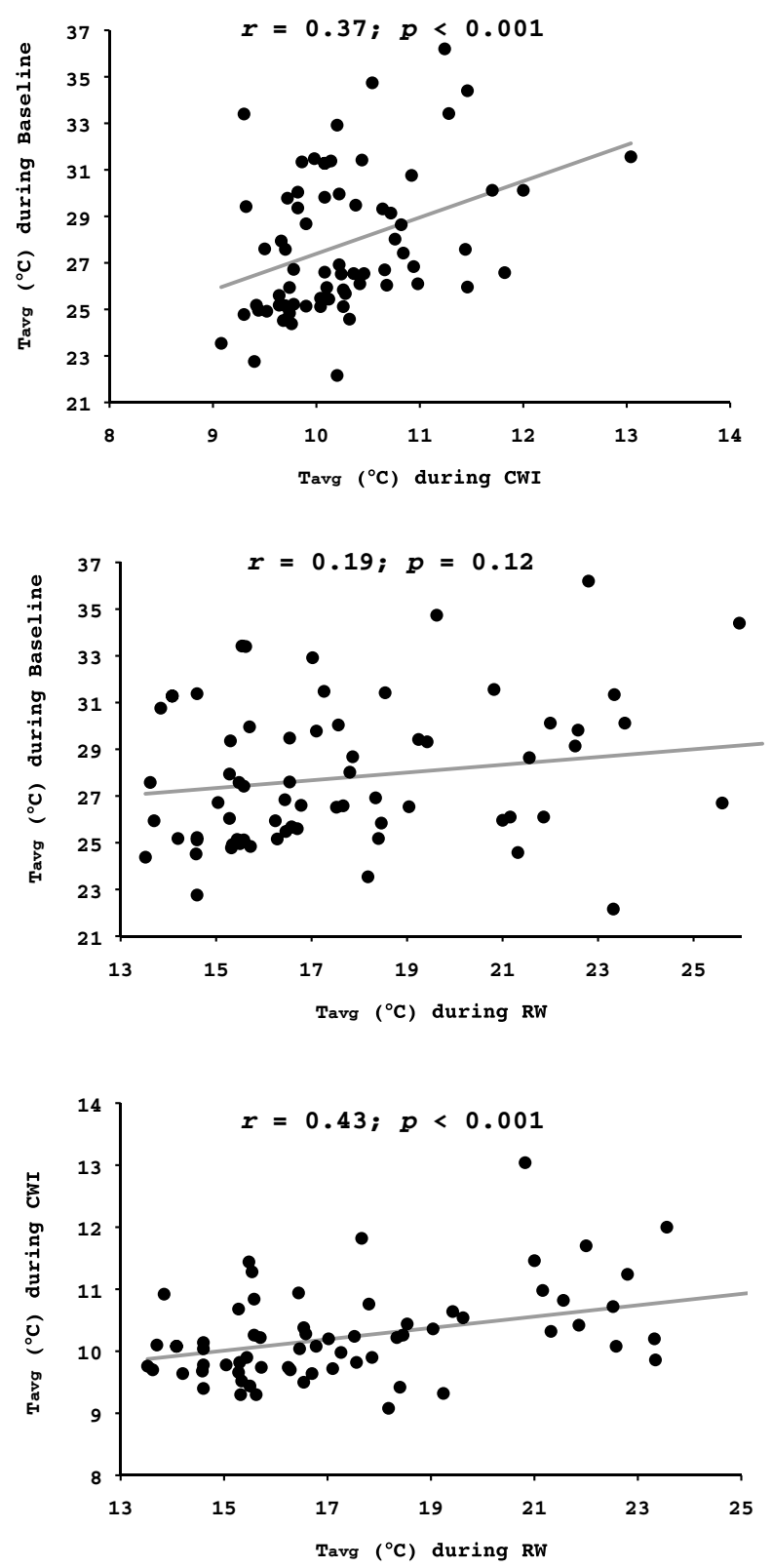

30-min cold-water immersion phase and the 15-min spontaneous rewarming phase (lower graphs) in (a) all fingers of the right hand and (b) all toes of the right foot

that the response is heterogeneous within different regions of a limb, and differ between hand and foot, and accordingly, the response of a specific region is plausibly not generalizable. In the present study, examining the skin temperature reaction of all immersed segments of the hand and foot in a large cohort of normothermic individuals, a weak correlation was observed between the fingers and toes during rewarming and a tendency of correlation between 

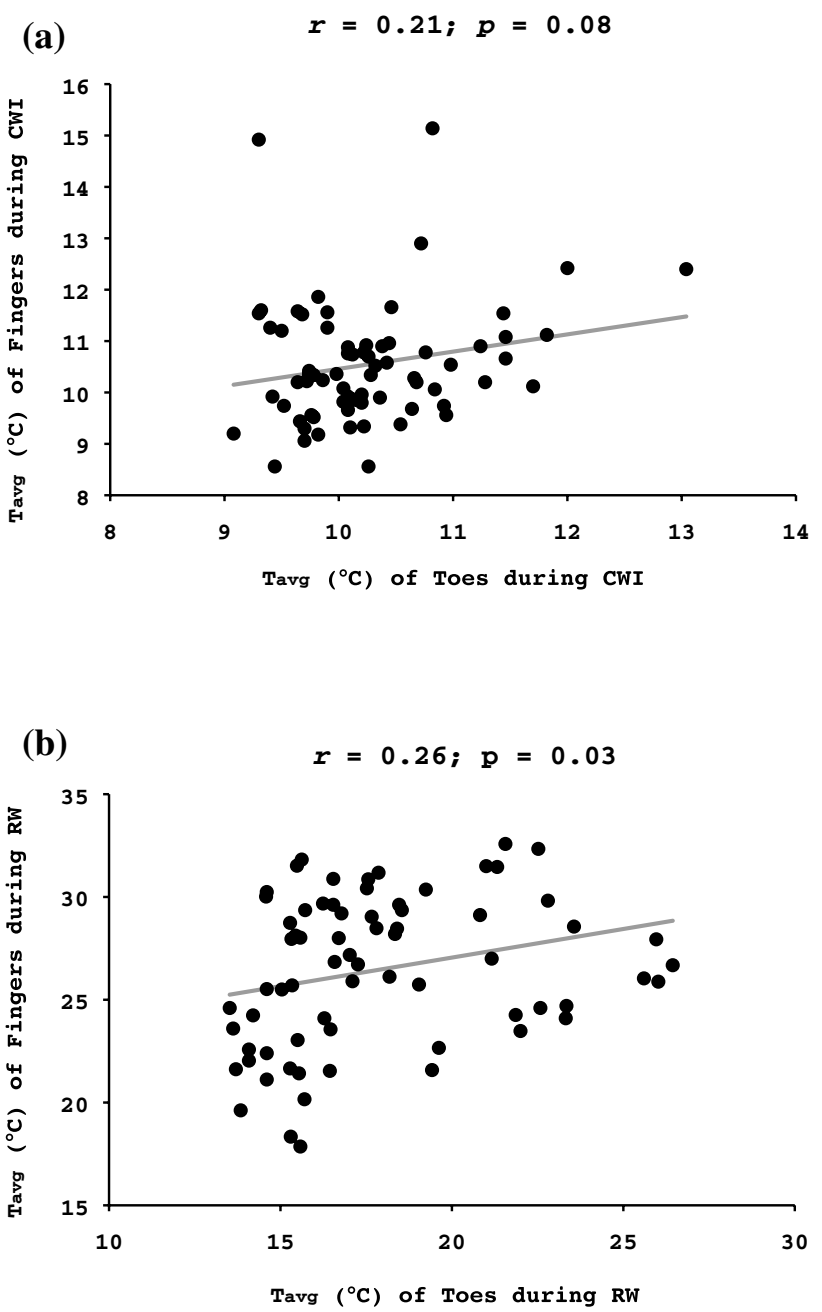

Fig. 5 Pearson's product-moment correlation between the average temperature $\left(T_{\text {avg }}\right.$ ) of all fingers of the right hand and all toes of the right foot during (a) the 30-min cold-water immersion phase and (b) the 15-min spontaneous rewarming phase

the fingers and toes was found during local cooling; there were no correlations between the hand and the foot neither during cooling nor rewarming. Hence, from a practical viewpoint, current findings confirm and extend previous evidence (Chen et al. 1996; Cheung and Mekjavic 2007; Reynolds et al. 2007) that in a given individual, the local thermal response to cooling is not transferable to other body regions. Considering the weak correlations between finger and toe temperature responses in the present study, including 70 subjects, it is not surprising that no tendencies of such correlations were revealed in the study by Cheung and Mekjavic that included only 10 subjects and investigated only the CWI phase; a power analysis revealed that 58 subjects was needed to exhibit a correlation between finger and toe temperature responses during the present RW. Presumably, in a larger cohort, a statistically significant yet weak correlation between finger and toe temperature responses
- Finger II

- Toe II

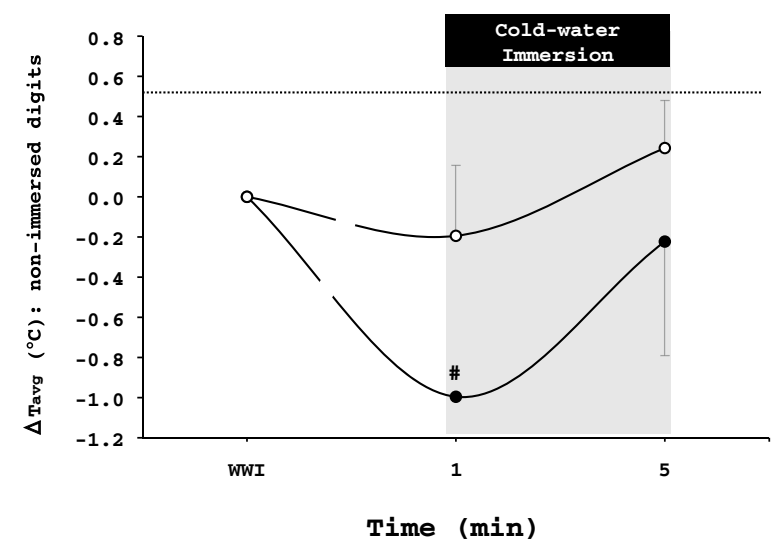

Fig. 6 Changes from the warm-water immersion (WWI) phase in the average temperature $\left(T_{\text {avg }}\right)$ of the non-immersed finger II and toe II during the hand and foot cold-water immersion test, respectively. Values are mean \pm SD. \# Significant difference from the previous timepoint $(p \leq 0.05)$

would be revealed also for the CWI phase. Regardless, such weak correlations have no practical consequence. The sensitivity of the cold-provocation test to predict cold injury still needs to be established (cf. Cheung 2015); yet present results imply that the test's specificity is not sufficient to justify it being used to, based on the response of a single finger, toe, hand, or foot, identify individuals with a general high risk of developing cold injury.

During the CWI phase, the toes exhibited a more profound drop in $T_{\text {avg }}$ and less of a CIVD response than did the fingers. After the cessation of the cold stimulus, a more protracted vasoconstriction was also observed in the foot, reflecting an impaired RW response. These findings appear to be in line with those from epidemiological studies (DeGroot et al. 2003; Juopperi et al. 2002) showing that the feet, and particularly the toes, are more vulnerable to cold injury than are the hands/fingers. The mechanisms underlying the heterogeneous thermal response of the two limbs to identical local cold stimuli remains to be established; yet, functional and structural vascular differences should be considered. Thus, presumably as a consequence of a considerably higher hydrostatic pressure loading, in resting humans, precapillary vessels of the distal leg exhibit considerably higher myogenic tone than do the corresponding vessels of the arm (Eiken and Kölegård 2004; Eiken et al. 2014), and blood flow per mass unit is considerably lower in the foot than in the hand (for review, see Taylor et al. 2014).

A number of studies have suggested that the skin-temperature reactions of the digits during local cooling are dependent, at least to some extent, on their pre-immersion 
- Hand test

O Foot test

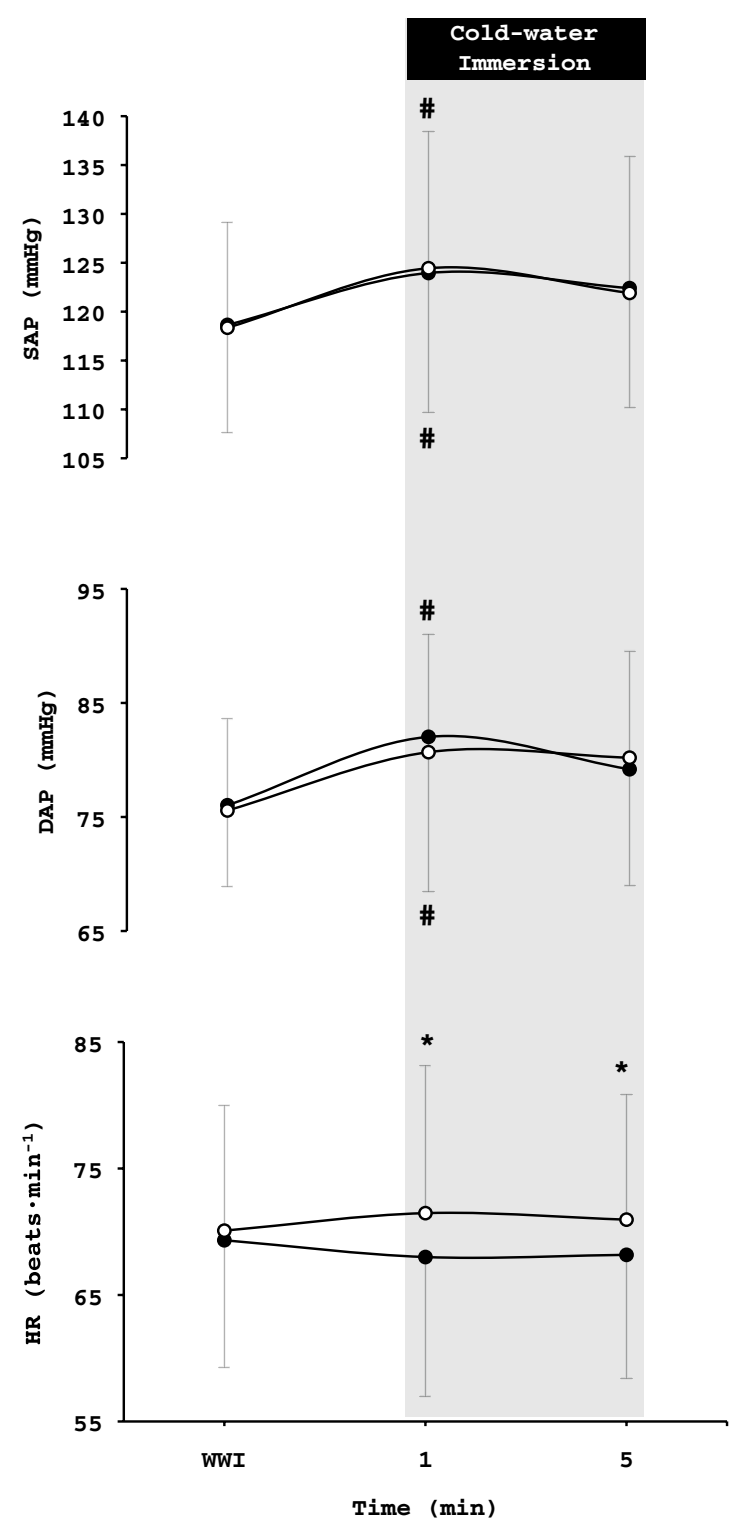

Fig. 7 Changes from the warm-water immersion (WWI) phase in systolic (SAP) and diastolic (DAP) arterial pressure, and heart rate (HR) during the hand and foot cold-water immersion test, respectively. Values are mean \pm SD. *Significant difference between hand and foot test $(p<0.05){ }^{\#}$ Significant difference in arterial pressure from the previous phase $(p<0.05)$

temperature (Greenfield et al. 1952; Yamazaki 2010; Keramidas et al. 2014, 2015). However, in the current study, we failed to confirm such a relation, as indicated by the weak correlation in both limbs between $T_{\text {avg }}$ during the baseline and CWI phases. Likewise, the RW response of the limbs was independent of their thermal status during the baseline phase. Yet, the RW response of the hand and foot was closely associated with its respective response during the CWI phase, a correlation that seemed to be stronger for the hand.

In clinical settings, the assessment of cold sensitivity, assuming to predict vulnerability to cold injury, is commonly based on the skin-temperature response of the limb during a period of spontaneous RW following a 2-min coldprovocation test (Davey et al. 2013; Eglin et al. 2013). Yet, in keeping with the current finding, it has been shown that the magnitude of the rewarming response is largely dependent on the duration of the cooling phase (Wolff and Pochin 1949), during which a fall in the temperature of deeper tissue layers is induced (Barcroft and Edholm 1943). Hence, considering the aforementioned relation between basal temperature and the thermal response to CWI, as well as the slower cooling rate of the foot, that may be due to its greater mass to surface area (cf. Jay and Havenith 2004), present results might imply that a longer cold-provocation than $2 \mathrm{~min}$ is warranted when the cold sensitivity of the foot is evaluated, or is compared with that of the hand.

Judging by the HR, but not the arterial pressure, responses, the cold-water immersion of the foot evoked a greater overall sympathetic reaction; a similar response has been reported previously (Amon 2009). Any enhanced sympathetic excitation during the foot cold test might be a result of the greater mass area submersed to cold water in this condition (cf. Sendowski et al. 1997). In this regard, the findings by Larra et al. (2015) showing that a bilateral foot cold-pressor test exaggerated the elevations in HR and the salivary alpha-amylase that were induced by a unilateral hand cold test are also of interest.

During the latter part of the CWI and during the RW, temperature was perceived considerably more uncomfortable and painful in the foot trial than the hand trial. Conceivably, this difference in perceived discomfort/pain reflected concomitant lower temperatures in the toes than the fingers; during this period, skin temperatures were, by contrast, generally higher in the F-MT than the H-MC region. Regardless of the reason, the exaggerated discomfort in the toes during and following a given cold stress is noteworthy considering that cold injuries appear to be more common in the toes than the fingers (DeGroot et al. 2003; Juopperi et al. 2002) and that behavioral alterations are regarded our first line of defense against cold environments (Mekjavic and Eiken 2006). In field conditions, however, it is commonly easier to behaviorally respond to cold discomfort in the hands (add insulation, and rewarming etc) than in the feet.

Upon immersion to cold water, a transient cutaneous vasoconstriction was observed in the non-immersed digits, but not in the other segments of the limbs. Although the mechanisms underlying this short-lasting vasoconstriction are not fully understood, it has been suggested 
to be mediated either via a reflex response to a noxious stimulus, and/or to be the action of a central mechanism elicited by the fall in blood temperature (Folkow et al. 1963; Kregel et al. 1992; Marshall et al. 1990; Pickering 1932). Notably, in the present study, the "indirect" vasoconstriction in the non-immersed digits was more pronounced in the contralateral finger than in the contralateral toe. The mechanisms underlying this discrepancy need to be further investigated. A blunted neural stimulus for the foot, resulting from a slower initial cooling rate and a smaller absolute drop in skin temperature, might have contributed to the weaker indirect vasoconstriction upon the foot CWI, even though the subject ratings of thermal sensation and pain do not support this notion.

Although the study was not designed to reveal seasonal changes, it spanned over 4 months, the latter two of which were winter months. Conspicuously, subjects investigated in January and February exhibited colder toes/feet during CWI and RW and a trend to colder fingers/hands during CWI. Whether these differences are attributable to the lower outdoor temperature in January and February or to other seasonal factors, e.g., physical activity level during the New Year's holidays etc, remains to be investigated. Regardless, the seasonal differences in local temperature responses observed in the present study presumably had little impact on the main study conclusion that the thermal response of one limb is not transferable to the other limb.

The baseline autonomic and subjective responses of the participants did not differ between the two cold tests. Cortisol spillover has been reported $\sim 15 \mathrm{~min}$ after a bilateral foot, but not after a unilateral hand, cold-pressor test (Larra et al. 2015). In view of this, it might be argued that the present 15-min interval between the tests was too short to allow full recovery. Nevertheless, any risk of confounding present overall results by any carryover effects from the first to the second CWI was minimized by the counterbalanced order of the trials.

In conclusion, the present findings demonstrate that the skin-temperature responses of the fingers/hand are not transferable to the toes/foot or vice versa, either during or after local cooling. Although the sensitivity of the coldprovocation test to predict cold injuries still needs to be determined, current results show that its use as a prognostic tool, if at all, must be limited to the tested limb.

Acknowledgements Open access funding provided by Royal Institute of Technology. The current project was supported by grants from the Swedish Armed Forces (No: 922: 0905). We are grateful to all the subjects for their participation. We would also like to thank Björn Johannesson for technical assistance and Eddie Bergsten for developing the analysis program.

\section{Compliance with ethical standards}

Conflict of interest The authors state that there is no personal or financial conflict of interest in the present study.

Open Access This article is distributed under the terms of the Creative Commons Attribution 4.0 International License (http:// creativecommons.org/licenses/by/4.0/), which permits unrestricted use, distribution, and reproduction in any medium, provided you give appropriate credit to the original author(s) and the source, provide a link to the Creative Commons license, and indicate if changes were made.

\section{References}

Ahle NW, Buroni JR, Sharp MW, Hamlet MP (1990) Infrared thermographic measurement of circulatory compromise in trenchfoot-injured Argentine soldiers. Aviat Space Environ Med 61(3):247-250

Amon M (2009) Effect of "sleep high-train low" hypoxic training on cold induced vasodilatation (CIVD) response in fingers and toes. Jozef Stefan International Postgraduate School, Ljubljana, Slovenia

Barcroft H, Edholm OG (1943) The effect of temperature on blood flow and deep temperature in the human forearm. J Physiol 102(1):5-20

Brändström H, Grip H, Hallberg P, Gronlund C, Angquist KA, Giesbrecht GG (2008) Hand cold recovery responses before and after 15 months of military training in a cold climate. Aviat Space Environ Med 79(9):904-908

Chen F, Liu ZY, Holmer I (1996) Hand and finger skin temperatures in convective and contact cold exposure. Eur J Appl Physiol Occup Physiol 72(4):372-379

Cheung SS (2015) Responses of the hands and feet to cold exposure. Temperature 2(1):105-120

Cheung SS, Mekjavic IB (2007) Cold-induced vasodilatation is not homogenous or generalizable across the hand and feet. Eur $\mathrm{J}$ Appl Physiol 99(6):701-705. doi:10.1007/s00421-006-0383-6

Daanen HA, van der Struijs NR (2005) Resistance Index of Frostbite as a predictor of cold injury in arctic operations. Aviat Space Environ Med 76(12):1119-1122

Davey M, Eglin C, House J, Tipton M (2013) The contribution of blood flow to the skin temperature responses during a cold sensitivity test. Eur J Appl Physiol 113(9):2411-2417. doi:10.1007/ s00421-013-2678-8

DeGroot DW, Castellani JW, Williams JO, Amoroso PJ (2003) Epidemiology of U.S. Army cold weather injuries, 1980-1999. Aviat Space Environ Med 74(5):564-570

Eglin CM, Golden FS, Tipton MJ (2013) Cold sensitivity test for individuals with non-freezing cold injury: the effect of prior exercise. Extrem Physiol Med 2(1):16. doi:10.1186/2046-7648-2-16

Eiken O, Kölegård R (2004) Comparison of vascular distensibility in the upper and lower extremity. Acta Physiol Scand 181(3):281287. doi:10.1111/j.1365-201X.2004.01291.x

Eiken O, Mekjavic IB, Kölegård R (2014) Blood pressure regulation $\mathrm{V}$ : in vivo mechanical properties of precapillary vessels as affected by long-term pressure loading and unloading. Eur $\mathbf{J}$ Appl Physiol 114(3):499-509. doi:10.1007/s00421-013-2758-9

Evans JD (1996) Straightforward statistics for the behavioral sciences. Brooks/Cole Publishing, Pacific Grove, Calif., USA

Folkow B, Fox RH, Krog J, Odelram H, Thoren O (1963) Studies on the reactions of the cutaneous vessels to cold exposure. Acta Physiol Scand 58:342-354 
Francis TJ, Golden FS (1985) Non-freezing cold injury: the pathogenesis. J R Nav Med Serv 71(1):3-8

Greenfield AD, Shepherd JT, Whelan RF (1952) Circulatory response to cold in fingers infiltrated with anesthetic solution. J Appl Physiol 4(10): 785-788

Jay O, Havenith G (2004) Finger skin cooling on contact with cold materials: an investigation of male and female responses during short-term exposures with a view on hand and finger size. Eur $\mathbf{J}$ Appl Physiol 93(1-2):1-8. doi:10.1007/s00421-004-1146-x

Juopperi K, Hassi J, Ervasti O, Drebs A, Nayha S (2002) Incidence of frostbite and ambient temperature in Finland, 1986-1995. A national study based on hospital admissions. Int J Circumpolar Health 61(4):352-362

Keramidas ME, Kölegård R, Mekjavic IB, Eiken O (2014) Acute effects of normobaric hypoxia on hand-temperature responses during and after local cold stress. High Alt Med Biol 15(2):183191. doi:10.1089/ham.2013.1131

Keramidas ME, Kounalakis SN, Eiken O, Mekjavic IB (2015) Effects of two short-term, intermittent hypoxic training protocols on the finger temperature response to local cold stress. High Alt Med Biol 16(3):251-260. doi:10.1089/ham.2015.0013

Kregel KC, Seals DR, Callister R (1992) Sympathetic nervous system activity during skin cooling in humans: relationship to stimulus intensity and pain sensation. J Physiol 454:359-371

Larra MF, Schilling TM, Rohrig P, Schachinger H (2015) Enhanced stress response by a bilateral feet compared to a unilateral hand cold pressor test. Stress 18(5):589-596. doi:10.3109/10253890.2 015.1053452

Lewis T (1930) Observations upon the reactions of the vessels of the human skin to cold. Heart 15:177-208

Marshall JM, Stone A, Johns EJ (1990) Analysis of vascular responses evoked in the cutaneous circulation of one hand by cooling the contralateral hand. J Auton Nerv Syst 31(1):57-66

Mathew L, Purkayastha SS, Rai RM (1973) Effect of cold acclimatization on heat output and occurrence of frost-bite in rats. Indian J Exp Biol 11(3):230-232

Mathew L, Talwar JR, Purkayastha SS, Mahotra MS (1974) Prediction of susceptibility to cold injury in monkeys. Selected topics in environmental biology. Interprint, New Delhi

Mekjavic IB, Eiken O (2006) Contribution of thermal and nonthermal factors to the regulation of body temperature in humans. J Appl Physiol 100(6):2065-2072. doi:10.1152/ japplphysiol.01118.2005

Morrison SA, Gorjanc J, Eiken O, Mekjavic IB (2015) Finger and toe temperature responses to cold after freezing cold injury in elite alpinists. Wilderness Environ Med 26(3):295-304. doi:10.1016/j.wem.2014.12.026

O'Brien C (2005) Reproducibility of the cold-induced vasodilation response in the human finger. J Appl Physiol 98(4):1334-1340. doi:10.1152/japplphysiol.00859.2004

Pickering GW (1932) The vasomotor regulation of heat loss from the human skin in relation to external temperature. Heart 16:115-135

Reynolds LF, Mekjavic IB, Cheung SS (2007) Cold-induced vasodilatation in the foot is not homogenous or trainable over repeated cold exposure. Eur J Appl Physiol 102(1):73-78. doi:10.1007/ s00421-007-0566-9

Rissanen S, Rintamäki H (2009) Extremity cooling and rewarming rates during military activities in winter. Paper presented at the RTO Human Factors and Medicine Panel (HFM), Helsinki, Finland

Ruijs AC, Jaquet JB, Brandsma M, Daanen HA, Hovius SE (2008) Application of infrared thermography for the analysis of rewarming in patients with cold intolerance. Scand J Plast Reconstr Surg Hand Surg 42(4):206-210. doi:10.1080/02844310802033943

Sendowski I, Savourey G, Besnard Y, Bittel J (1997) Cold induced vasodilatation and cardiovascular responses in humans during cold water immersion of various upper limb areas. Eur J Appl Physiol Occup Physiol 75(6):471-477. doi:10.1007/ s004210050191

Taylor NA, Machado-Moreira CA, van den Heuvel AM, Caldwell JN (2014) Hands and feet: physiological insulators, radiators and evaporators. Eur J Appl Physiol 114(10):2037-2060. doi:10.1007/s00421-014-2940-8

Van der Struijs NR, Van Es EM, Raymann RJ, Daanen HA (2008) Finger and toe temperatures on exposure to cold water and cold air. Aviat Space Environ Med 79(10):941-946

Wilson O, Goldman RF (1970) Role of air temperature and wind in the time necessary for a finger to freeze. J Appl Physiol 29(5):658-664

Wolff HH, Pochin EE (1949) Quantitative observations on vascular reactions in human digits in response to local cooling. Clin Sci (Lond) 8(3):145-154

Yamazaki F (2010) Local ascorbate administration inhibits the adrenergic vasoconstrictor response to local cooling in the human skin. J Appl Physiol (1985) 108(2):328-333. doi:10.1152/ japplphysiol.00814.2009 